\title{
Trust as an Element of the Functioning of the Information System in Management in Conditions of Forced Remote Work
}

\author{
Tomasz Lis ${ }^{1}$, Aleksandra Ptak ${ }^{1, *(1)}$ and Marek Lis ${ }^{2}$ \\ 1 Faculty of Management, Czestochowa University of Technology, Armii Krajowej 19B, \\ 42-200 Czestochowa, Poland; tomasz.lis@pcz.pl \\ 2 Faculty of Electrical Engineering, Czestochowa University of Technology, Armii Krajowej 17, \\ 42-200 Czestochowa, Poland; marek.lis@pcz.pl \\ * Correspondence: aleksandra.ptak@pcz.pl; Tel.: +48-343-250-395
}

Citation: Lis, T.; Ptak, A.; Lis, M. Trust as an Element of the Functioning of the Information System in Management in Conditions of Forced Remote Work. Energies 2021, 14, 7425. https://doi.org/ $10.3390 /$ en14217425

Academic Editors: Joanna Paliszkiewicz and Donato Morea

Received: 1 October 2021

Accepted: 3 November 2021

Published: 8 November 2021

Publisher's Note: MDPI stays neutral with regard to jurisdictional claims in published maps and institutional affiliations.

Copyright: (c) 2021 by the authors. Licensee MDPI, Basel, Switzerland. This article is an open access article distributed under the terms and conditions of the Creative Commons Attribution (CC BY) license (https:// creativecommons.org/licenses/by/ $4.0 /)$.

\begin{abstract}
Information management, an important element of which is the information system, has a direct impact on the functioning of a company, including its competitive position. Information management is related to the shape of the organizational culture, represented, inter alia, by the context of trust, relationship, and communication. The shape of the organizational culture, including the functioning of the information system, is particularly influenced by factors (usually external) that appear in a sudden and unpredictable manner. This impact increases with the intensity and scale of their influence. The recent COVID-19 pandemic should undoubtedly be considered such a factor. As a result, many enterprises suddenly had to switch to remote work. The aim of this paper is to analyze the essence and recognize the impact of the forced transition to a remote form of work on trust as a shaping and effective factor in the functioning of the company's information system. To achieve this goal, the results of qualitative research conducted by the authors during the period March 2020-February 2021 and quantitative research conducted in February 2021 were used. In connection with the conducted research, it was found that trust is a very important factor influencing the efficiency and quality of employees' work. It was also found that the forced need to switch to remote work mode was a problem for most people. This was influenced by both the time of the pandemic, as well as technical and organizational problems. As a result of observations, own experiences, interviews, and a questionnaire survey, the authors state that the necessity to switch from traditional to remote work resulted in an increase in the costs of functioning of people, including employees.
\end{abstract}

Keywords: information system; management; trust; relations

\section{Introduction}

The research problem of this paper is related to the influence of trust on the functioning of the information system of enterprises operating under the conditions of remote working. This applies to the situation of a sudden and forced necessity to switch to remote mode. The enterprise information system is one of the most important elements of enterprise management in the conditions of volatile and uncertain markets [1]. This is due to the area and subject of management, which is information and knowledge. These factors, being one of the most important intangible assets of the company, directly affect its competitive position [2]. The information systems of enterprises cover not only the area of information processing but also the use of information. They are interested in all activities and events related to the acquisition, processing, and use of information [3]. As emphasized by $\mathrm{Ch}$. W. Choo, the efficiency of information management, and at the same time the information system, is largely influenced by the form of organizational culture [4]. One of the most important factors in this regard is trust.

Another aspect in relation to the research problem undertaken in this work was the issue of increased electricity consumption in households as a result of the forced and 
widespread transition to the remote form of work. The increase in consumption contributed to an increase in maintenance costs; it could also affect the greater failure frequency of installations and devices. These factors could have had an impact on the noticeable increase in the nervousness of employees, as well as disruptions in the work and schoolwork of the household members.

Taking up the issues raised in the work led to the emergence of specific research questions. Their setting was closely related to the authors' participation in the functioning of the community in the conditions of the progressive effects of the COVID-19 pandemic. The conducted observations allowed the author to draw attention to two basic issues. The first was the potential deterioration of relations and relationships in enterprises, which was caused by the need to switch to remote work mode. The second, caused by the same factor, was the emergence of disruptions in the functioning of information systems in enterprises. An accompanying observation was made that the forced transition to a remote form of work will result in an increase in individual labor costs, the source of which will be, inter alia, increased activity in the use of electricity supplies. This observation resulted from the fact that, on working days, in the period from 6 a.m. to 4 p.m., the activity of energy consumption in households is low-professional work outside home and education in schools. In connection with the conducted observations and the resulting observations, the authors asked research questions, which were then reflected in the set goal and research hypotheses:

- What are the basic problems in managing an enterprise in the event of the necessity to switch to a forced form of remote work, in particular with regard to the functioning of the information system?

- Does the necessity to switch to a forced form of remote work affect the effectiveness of the company's information system?

- Does the transition of the enterprise to a forced remote form of remote work affect trust in the enterprise, and if so, how?

In the research questions posed, and thus in the hypotheses, the issue of the increase in the costs of individual electricity consumption was not addressed. The use of energy in the place of residence when, under normal conditions, the household members perform their duties outside, and, to a large extent, the fact that their possibility of leaving these places is more limited, are doubtless factors contributing to stress. The increase in energy costs as a stress factor has been treated as one of those influencing trust and indirectly disrupting the functioning of information systems. In this regard, a survey asked questions regarding the increase in consumption costs. In addition, these issues were reflected in the problems of physical access to ICT-related work tools, resulting from the number of people working and learning remotely. This issue makes it possible to make inferences regarding the increase in the analyzed costs. In this thematic area, the respondents were also asked to comment on the increase in the number of failures of equipment using electricity related to work/distance learning.

The issue of trust can be considered in terms of interpersonal relations and at the interface between humans and technology. Both dimensions, as noted by P. Holland, B. K. Cooper, A. Pyman, and J. Teicher have a great influence on the information system and information management. Any disruption in this respect translates into disruptions in the system and management [5].

In this paper, the authors analyzed the essence and significance of trust in the event of the sudden need to switch to the remote operation of enterprises and their employees. This issue is particularly topical due to the prevailing epidemiological crisis of COVID-19. At the beginning of 2020, many enterprises faced the necessity of a forced and sudden transition to remote work. This was the cause of many problems, the nature of which lay in the unpreparedness of equipment, organization, and human resources. The human dimension resulted, inter alia, from the need for the cooperation of employees who were not in direct physical contact with one another. This problem is related to organizational issues. Another problem was the necessity for people who were family members and 
working in different places to function in one place; additionally, it was influenced by the remote teaching of children also being carried out at home.

This new and sudden situation had a significant impact on the form of organizational culture, including relationships, communication, and trust. This article uses qualitative research-in-depth interviews, discussions, and participant observation, as well as quantitative research related to the survey conducted by the authors.

The main research goal of the paper is the analysis of the essence and recognition of the impact of the forced transition to a remote form of work on trust as a shaping and effective factor in the functioning of the company's information system.

An important element of such a goal is the causative factor of functioning on the basis of remote work. A completely different situation occurs in the case of enterprises naturally and spontaneously oriented towards this type of work, and those which, as a result of external factors, faced the need to introduce it. The undertaken topic is to help to understand the impact of the new reality on the functioning of the enterprise, represented by the functioning of the information system. As a result, the factors influencing the effectiveness of the transition to remote mode are to be identified, especially in the context of trust.

The formulated goal, combined with the conducted literature research and the observation of the practice related to the transition of enterprises and employees to the remote mode and the impact of this action on the functioning of the information system, prompted the authors to put forward the following hypotheses:

- A forced and sudden transition to remote work has a negative impact on the functioning of the company's information system.

- A forced and sudden transition to remote work has a negative impact on trust in the enterprise.

\section{Literature Review}

\subsection{Information System during Remote Work}

An information system is a set of elements related to basic operations on information [6]. These activities include obtaining, processing, disseminating, analyzing, and using information. According to J. Kisielnicki, there are many different definitions of the information system in the literature [7]. The information system consists of people, as well as technical elements, among which ICT elements play a very important role [8]. People- users of information-are the element that determines the form and functioning of the system on a technical level, and at the same time they make decisions concerning its effectiveness and efficiency [9].

The organizational structure is the element that creates the structure of the enterprise. The information system, in turn, is the element that provides access to the energy factorthe supplying and driving component. This is the role of information in the company [10]. It results directly from the importance of information in human life [11]. It plays the role of the causative agent of all activities. At the same time, it is the result of all activities, which are, at the same time, the causative factor for the activities of the source and other participants in economic life [12]. The described role of information clearly shows that disruptions in the functioning of the information system always have a negative impact on the enterprise, including its competitive position [13]. It should be noted that the impact is immediate.

This is confirmed by the results of research conducted in 2010 by Andersen Consulting and The Economist Intelligence Unit. The research concerned factors and skills that were key to the effectiveness of company management. According to $94 \%$ of respondents, the key element is the ability to communicate, which is the basis of the information system [14]. The basis of efficiency and effectiveness of communication is trust.

As noted by A. Szaniawska and Grochowska, the information system is influenced by the following: recipients of information, collections of information-most often stored on IT media, technical infrastructure-mostly related to IT, the way of functioning-organization 
management, and existing relations-including interpersonal relations [15]. The presented factors can be divided into two groups: technical and related to human functioning. This division is important in terms of the possibility and ability to shape the system [16]. The technical infrastructure playing the role of a tool is not a problem in this respect. Factors related to human functioning, i.e., the methods of management and maintaining relationships, play a key role. Their shaping is a continuous process [17]. At the same time, it is an element sensitive to disturbances, especially sudden, unexpected ones that have a high impact on the enterprise. The most important of these are those that affect the structure and the power factor. These include the global COVID-19 pandemic.

Its appearance necessitated isolation. In order to protect health, as well as being a formal requirement, in many companies it was necessary to switch to a remote form of work. This form is known as teleworking [18]. In relation to enterprises and workplaces adapted to this type of work, teleworking is considered to be more efficient than the traditional form [19]. However, if one needs to suddenly and quickly switch to remote work, one should expect problems. These are related to stress, technical limitations-hardware, application, and general compulsion.

In a situation that had such a large impact on the economy, such as COVID-19, the transition to remote work was the only option for many companies to continue their operations. "But you have to remember, that it is not enough to hand over laptops to employees. Business readiness to act 'remotely' has to be comprehensive. The day-to-day operation of the business covers many different areas. The company is the business profile, the condition of employees and infrastructure. It is also time, processes, documents, legal regulations" [20]. ICT provides tools for organizing and conducting remote work [21]. It should be assumed that the problem, especially at the initial stage, is the ability to provide employees with access to computer hardware and software. However, the biggest problem is the organization of the work itself by users. This is connected to the necessity to reorganize the company's information system [22]. As a result, there is an interference in the system that feeds the organization with the driving factor, i.e., information.

Based on the conducted research, it is stated that, in Poland, about $20 \%$ of employees perform work, the form and nature of which allows them to switch to remote mode. This form of professional activity was adopted by $14 \%$ of employees as a result of the pandemic [23]. The traditional form gives the management staff, but also the employees themselves, the possibility of physical contacts, including observing, controlling, supervising, and organizing individual and mutual work. The remote form introduces major changes in this regard. Under such conditions, mutual trust is a key factor in user collaboration in the information system. Its determinant is the ability to be as undisturbed and as efficient as in the form of the traditional work of individuals, especially in terms of cooperation.

Remote work, due to the lack or, to a significant degree, the limitation of direct contacts, requires employers and decisionmakers to conduct control activities. In the report "Possibilities of using remote work in enterprises and public institutions", the following control tools are mentioned: regular tele- and videoconferences, regular summaries sent by e-mail, electronic monitoring regarding, e.g., login and logout times, unannounced telephone contacts related to expressing opinions and/or submitting reports. One of the most important tools are Key Performance Indicators (KPIs). The report stated that this form of control was declared by $29 \%$ of employees of Polish enterprises [24]. The literature indicates that KPIs make it possible to model/determine the expected values of work efficiency. Historical data is used for this. Established expected values of effectiveness are to control, but above all, to motivate to work. This issue is particularly important in connection with the sudden need to switch to the remote form of work in conditions of general, not only professional, uncertainty [25]. 


\subsection{Trust as the Factor of the Effectiveness of the Information System in the Conditions of Forced Remote Work}

As noted in the "Voice of the European workforce" report, trust plays an important role in the company's ability to adapt to sudden changes-such as in the case of COVID-19. For $40 \%$ of European workers, it was the trust of superiors, management, and leaders that mattered. Trust among colleagues was important according to $38 \%$ of respondents. Among Polish employees, the greatest recognition was found among employees, while the trust of leaders was ranked 4 th in terms of the number of responses. The report noted that professional networks also contributed to adaptation to change- $37 \%$ of European respondents. This position should also be viewed in terms of trust. Importantly, the respondents indicated that they counted on the trust of leaders and associates as the factor supporting changes, but also their professional work in general, also after the end of the pandemic. Additionally noteworthy are the results regarding the question of the factor that will be of greatest importance in the functioning of enterprises in the post-pandemic reality. The respondents decided that it would be the ability to adapt to new realities. This is to be fostered by the trust of the management and, in general, among colleagues [26].

Trust is a concept that is hard to define. Most often it can be viewed in the context of credibility or honesty [27]. Trust is the basic element of cooperation and collaboration. As A. Rudzewicz notes, "trust consists in respecting norms and moral and ethical principles. It manifests itself in the feeling of confidence towards the other person, as well as the possibility of relying on them" [28]. Mutual support, complementation, and help play an important role in trust. Cooperation very often takes place on the information plane [29]. The important factor of trust is the display and dissemination of information.

The importance of trust in management results from volatility, dynamics, and uncertainty as features of the contemporary economic reality. Organizations have to react quickly to emerging signals concerning upcoming opportunities or threats. The basis is an efficient, flexible information system ensuring the free flow of information. Trust in the company is a determinant, but it is also an element that creates the form of organizational culture [30]. Understandable and approved rules, procedures, and regulations; a good atmosphere; and appropriate interpersonal relations are factors that create trust. At the same time, the trust itself influences interpersonal relations and compliance with regulations and rules of operation [31]. Trust as a determinant of culture and relationships is the easiest way to shape it through direct contacts. Physical proximity is conducive to the emergence and resolution of disputes. Employees get to know each other, thus building mutual trust [32]. This factor does not occur in the case of remote work, where employees do not generally have the ability to maintain physical contact. The contacts then take place on the information plane with the use of ICT elements. The traditional form of work, as a result of physical contact, allows for the quick identification and solving of a number of problems. In the remote form of work, problems can most often be solved only on the information level [33]. Their identification, especially in enterprises that have been forced to switch to remote mode, is very difficult. In organizations adapted to and using remote forms of work, employees learn such cooperation, including creating an atmosphere of trust. In organizations where the transition to remote work occurs suddenly, this is a significant challenge [34].

Decisionmakers play a special role in managing times of crisis, including those related to the necessity of a sudden transition to a remote form of work. It is them who are responsible for maintaining good practices and shaping organizational culture in the new reality. One of the most important activities of decisionmakers, related to shaping relationships, including organizational culture in general, is the organization of physical, not remote, meetings. In times of forced remote work, this is difficult, but necessary. Such meetings must be held in a limited group and at a strictly defined time. In her research, D. Chmielewska-Buciek dealt with the issues of the identification, evaluation, significance, and features of organizational culture in the workplace, expressed by people in managerial positions. The authors stated that the approach of decisionmakers is conservative, with a low tolerance of uncertainty (which occurs as a factor in crisis situations with a pandemic 
dimension) and a high level of communication (difficult to maintain in times of a pandemic). As far as communication is concerned, it was found that what counts most is direct contact, which takes place directly in the event of the need arising. Maintaining this principle is one of the most important challenges of working in remote conditions, especially in situations of a sudden transition to this form of work. It is a new situation for employees, changing everything they knew on this level [35].

The issue of trust in the context of information systems is often associated with trust in IT equipment. It is about the user's belief that IT tools have a friendly interface, enable the performance of all tasks performed, are reliable, provide access to all the necessary information, and ensure effective transfer of data and information. With regard to information as a factor of cooperation, trust, according to V.M. Ribiere, gives the opportunity to choose the right sources of information [36]. Trust also contributes to faster information flow, faster information analysis, and the adaptation of the information provided to the actual needs of the recipient. This has a positive impact on the optimization of knowledge management and use [37]. Decisions are an important element of the information system. Trust has a positive effect on the improvement and acceleration of the decision-making process [38]. Trust in technology and people are closely related. This especially applies to the remote form of cooperation.

Trust in the context of the effectiveness of the information system can be considered from the point of view of the effectiveness of the organization. In this respect, it has a positive effect on "using economic resources in the most efficient way" [39].

\section{Research Methodology}

Taking into account the research problem, the basis of which was the understanding of the essence and impact of trust on the company's information system, especially in the conditions of a sudden and forced transition to a remote form of work, it was decided that the research methods used would be based on the following: the literature study; the quantitative study - a CAWI survey and qualitative research; participant observation; and discussions and in-depth interviews: individual, group, spontaneous, and planned. The choice of the qualitative research was dictated by their positive impact on cognitive issues, including the identification of weak signals and understanding the essence and mechanisms governing the research area [40].

Qualitative research contributed to the recognition and understanding of the problem. What is particularly important is that the relationships between the various identified factors were identified. The knowledge gained as a result of the analysis of undeveloped data was refined in the course of the interviews conducted. Their further specification took place in connection with the ongoing discussions. One of the identified problems was the attitude and nervousness resulting from the pandemic and the professional situation, which, in connection with remote work at home, was closely related to the living situationprivate life. This was noticeable in interviews and discussions, as well as in the emotional nature of statements in forums. In the opinion of the authors, the influence of this factor was limited during the discussion. Conversation in a wider group allowed the reduction of emotions, which was the result of making people aware that the problem also applies to other people.

Interviews conducted as part of the survey were conducted with employees from various levels of the organizational structure. It relied on undelivered data (posts in online forums) - 86, and evoked data related to the course of interviews during interviews - 27 [41]. Among the people interviewed were: 8 people in a managerial position and 19 employees whose scope of duties is related to the use of computers. During the course of the research, the authors collected verbal and visual data [42]. Data collection techniques used include individual interviews - 27, group discussion-6, and participant observation. Among the problems/limitations of qualitative research, the time of its conduct should be mentioned. The timing of the pandemic and the general nervousness, anxiety, and uncertainty of the future probably influenced the opinions expressed for some people. The collected data 
was analyzed using the following analysis: conversational, continuous comparative, and content [43]. The analysis of the obtained data was performed according to the principles of qualitative data analysis. They were based on continuous data analysis and iteration. The conclusions drawn each time had an impact on the further part of the research. The research was conducted with people who, according to the knowledge of the authors of the publication, had or could have knowledge related to the issues raised.

The idea behind quantitative research is to give specific measures to the analyzed phenomena. They allow for the generalization of the obtained results in relation to the entire population. Among the problems encountered by the authors of the publication in connection with the conducted quantitative research, one should indicate, as in the case of qualitative research, the time of their conduct. General nervousness and the complexity of everyday life were not conducive to a positive approach to filling in the questionnaire. To overcome this factor, the questionnaire consisted of not too many questions, which were simple to understand. The respondents were also informed about the significance of the survey, its low complexity, and the short time required to complete it.

The use of both qualitative and quantitative research is now a common approach in management sciences. This is due to the fact that each of them individually has certain limitations. The limitation in quantitative research is that it does not give good results in terms of observation and analysis of difficult social phenomena in which individuality plays an important role-approach, perception, and thinking. Such issues can be investigated using qualitative research. On the other hand, quantitative research makes it possible to analyze larger numbers of units and thus to define generalizations.

The qualitative research used is based on ethnographic research. The advantage of this approach is the ability to observe and analyze real behavior, not just simulated behavior.

As part of the qualitative research related to observation, discussions, and interviews, attention was paid to:

- Individual opinions on the transition of a person (employee), but also the organization, to a sudden and forced remote work mode;

- Possible problems in connection with the transition to remote work mode, concerning both the professional (organizational) and private spheres;

- Professional experience as part of working remotely, including in the current place of employment;

- Speed of adaptation to new working conditions;

- The ability of the organization to provide technical and application facilities for remote work;

- The form and course of cooperation as part of the performance of official duties in remote work conditions;

- Trust as an element of organizational culture before and after the forced and sudden transition to remote work, concerning the sphere of interpersonal contacts, but also those of a human-technician nature;

- Factors that influence the ability to smoothly transition from traditional work to remote work.

The above-mentioned issues were also the starting point for the research questions posed in the paper, as well as an important factor in the preparation of the survey.

The research conducted by the authors was accompanied by specific problems and limitations. These include the following: technical problems related to the possibility of reaching the respondents, general technical problems in the implementation of the survey, and the not entirely favorable attitude of people in relation to the expressed willingness to conduct an interview. The studies were conducted during the COVID-19 pandemic, which, in the authors' opinion, had an impact on the attitudes of people to participate in the studies. This was related to nervousness and the difficulty of predicting future events. It also resulted from the need for all family members to function in the professional and private sphere in the same rooms. 


\section{Results and Analysis of the Research-Trust as the Factor of the Efficiency of Information Systems in Conditions of Forced Remote Work}

The questionnaire, as part of the research problem, was carried out with the use of the Internet-the CAWI method. Due to the subject matter, working people aged 18 to 65 participated in the study. The questionnaire was sent to the email addresses of the authors' contacts. In this way, it was sent to 317 people. The authors also asked the person to whom the questionnaire was sent to send it to friends from their contact list. The respondents were informed that completing the questionnaire was anonymous, and at the same time returning it was tantamount to giving consent to the use of the results in the prepared scientific publication. The questionnaire was properly completed, i.e., its results could be included in the collective analysis, by 362 people. Nineteen questionnaires were completed in a way that forced the authors to reject them. Due to the fact that the discussed topic is related to the sudden and forced transition to remote work mode, the analysis only included surveys in which respondents confirmed such a transition (due to COVID-19 as a contributing factor). Using this approach, 204 questionnaires were qualified for the analysis. Such a large share of people who declared switching to the remote mode resulted from the fact that the authors of this paper, among their friends, had many people who worked outside the field of manual labor, traditionally using ICT tools.

Based on the qualitative research related to observation, discussions, and interviews, it was found that the transition to remote work forced by the pandemic situation was associated with high stress on the part of both employees and employers. This was stated by all the decisionmakers and employees interviewed. As part of the in-depth interviews regarding the causes of stress, the following answers were mainly given (this applies to both employees and decisionmakers):

- Uncertainty of the future, related to employment (employees) - as part of the interviews, 19 (out of 19) employees, but also 5 (out of 8) decisionmakers, functioning (employers)-6 decisionmakers;

- Uncertainty of the future related to the organization and the effects and efficiency of work, also with regard to cooperation (employees and employers) - 7 decisionmakers and 18 employees as part of interviews;

- Concerns relating to the ability to work at home in terms of organizational chaos in the place of residence, caused by the need to organize remote "work" places at the same time for more than one person (work, study) (employees) - 6 decisionmakers and 16 employees said so in the interviews.

In the case of people who had some experience in remote work and people up to 40 years of age, there were also answers indicating a lack or slight organizational concern related to the need to work remotely by a larger number of household members.

In most cases, as the observations and interviews show, the fears passed after some time. According to the authors, this was related to the necessity of a remote form of work, which simply influenced the need to deal with the problem. During the interviews, but also in discussions, the most frequent answer was: it is / was hard, but what do you do if there is no way out? As stated, one of the biggest problems in the organizational dimension was the provision of appropriate technical means-workplaces-and access to the Internet. In many companies, equipment was provided to employees only after some time. This problem was also indicated by four out of eight people interviewed who were employed in managerial positions. In a few cases, it was found that the respondents had access to the Internet via mobile networks, which, due to the simultaneous work of many people, as well as habits in using the network after work, did not always allow for normal work. According to the authors, it should be assumed that this problem affected a larger number of people.

By examining the issues of cooperation, relations, and trust with the use of observations, discussion, and interviews, it was found, especially in the initial period, that there was a large amount of chaos, uncertainty, and lack of coordination, and the emergence of conflict situations. Based on the interviews, it can be concluded that 7 out of 8 deci- 
sionmakers and 17 out of 19 employees highlighted this situation. Two decisionmakers described the scale of the problem as being significant. When asked about the quality of cooperation in the remote form and the previous traditional form, people with no experience in remote work always indicated its deterioration. This was indeed the case for many people with some experience, but whose companies had been operating on the traditional basis prior to the pandemic. This was also highlighted by the decisionmakers interviewed. Only two of them had some experience with remote work, yet all eight noted a deterioration in the quality of cooperation. This was especially true of the initial period; eighteen employees indicated it. Interestingly, the general factors accompanying the sudden and forced transition to remote work, as it turned out, had an impact on the reduction in the assessment of the level and course of cooperation. This was in relation to the quality of work on the equipment, via the Internet, conflicts at home, difficulties in establishing details remotely, etc.

The issue crowning and, in a way, summarizing the conducted qualitative research was the issue of factors that affected the non-conflict or, with limited negative impact, the transition from traditional to remote work. The determinant was the necessity and the suddenness of the transition. On the basis of observations, discussions, and interviews, the authors stated in this respect that they favor this:

- Flexibility of work-expressed in the ability to carry out tasks both stationary and remotely. The management should organize their duties so that individual employees perform them remotely from time to time - as part of the interviews, this was indicated by 8 (out of 8 ) decisionmakers and 14 (out of 19) employees;

- Organization of the company's IT (technical and application) facilities so that it is possible to switch to remote work at any time. In this regard, it was pointed out that the employee must report problems with the availability of IT tools on an ongoing basis and, if possible, help in this matter-as part of the interviews, this was indicated by 8 (out of 8 ) decisionmakers and 18 (out of 19) employees;

- Awareness of the possibility of a situation that may result in the reorganization of the way the enterprise operates-as part of the interviews, this was indicated by 6 (out of 8) decisionmakers and 11 (out of 19) employees.

Among the factors signaled by the surveyed factors, the last one deserves special attention. It is related to the human realization of the possibility of occurrence and the need to adapt to the situation, to a large extent, or to completely change current professional life.

Another research methodology used by the authors was quantitative research. This was carried out using the survey technique. Details related to the preparation and conduct of the study are presented at the beginning of this section.

In the survey, the smallest percentage was constituted by people aged 18 to 25 years$15.69 \%$. The largest percentage was constituted by people aged 25 to 41 years- $49.51 \%$. In turn, people aged over 41 to $65,34.80 \%$, was recorded. The study was slightly dominated by women- $52.45 \%$ of the respondents. Men accounted for $47.55 \%$ of the respondents. None of the respondents chose another answer.

On the basis of the obtained results, it can be concluded that, according to $51.96 \%$ of respondents, the forced transition to remote work by the pandemic was problematic. This was indicated mainly by women, $58.88 \%$, compared to $44.33 \%$ by men. Analyzing this issue depending on the age of the respondents, it was found that this item was most often selected by people over 41 years of age. People up to 25 years of age made up $21.88 \%$, and those aged 25 to 41 years of age made up $40.59 \%$. The obtained results indicate that, with age, the transition to sudden remote work was an increasing problem. According to $8.82 \%$, it was accompanied by significant problems. Distribution of the selections of this item also depended on gender: $13.08 \%$ women and $4.12 \%$ men. It can be concluded that this problem was felt primarily by women. Meanwhile, $7.84 \%$ of the respondents declared that they were completely problem free, and $10.78 \%$ of the respondents declared that it was not too complicated. Regarding the distribution of responses by gender: no problems, $12.37 \%$ men, $3.74 \%$ women; age of the respondents, $15.63 \%$ people under 25 years, $10.89 \%$ 
25 to 41 years, and $0 \%$ over 41 years. In the case of uncomplicated items, this distribution was as follows: $14.43 \%$ men, $7.48 \%$ women; $15.84 \%$ people aged 25 to 41 years, $12.50 \%$ up to 25 years, $82 \%$ over 41 years. As seen in Figure 1, 20.59\% of people did not have an opinion on this matter. Experience in this respect was an important factor in the process of forced and sudden transition to remote work. Among the people participating in the study, $81.37 \%$ had no experience and $7.35 \%$ had only slight experience. Only $0.49 \%$ (1 person) constantly worked remotely, 3.43\% did it often, and $7.35 \%$ declared that they had dealt with this form of work previously.

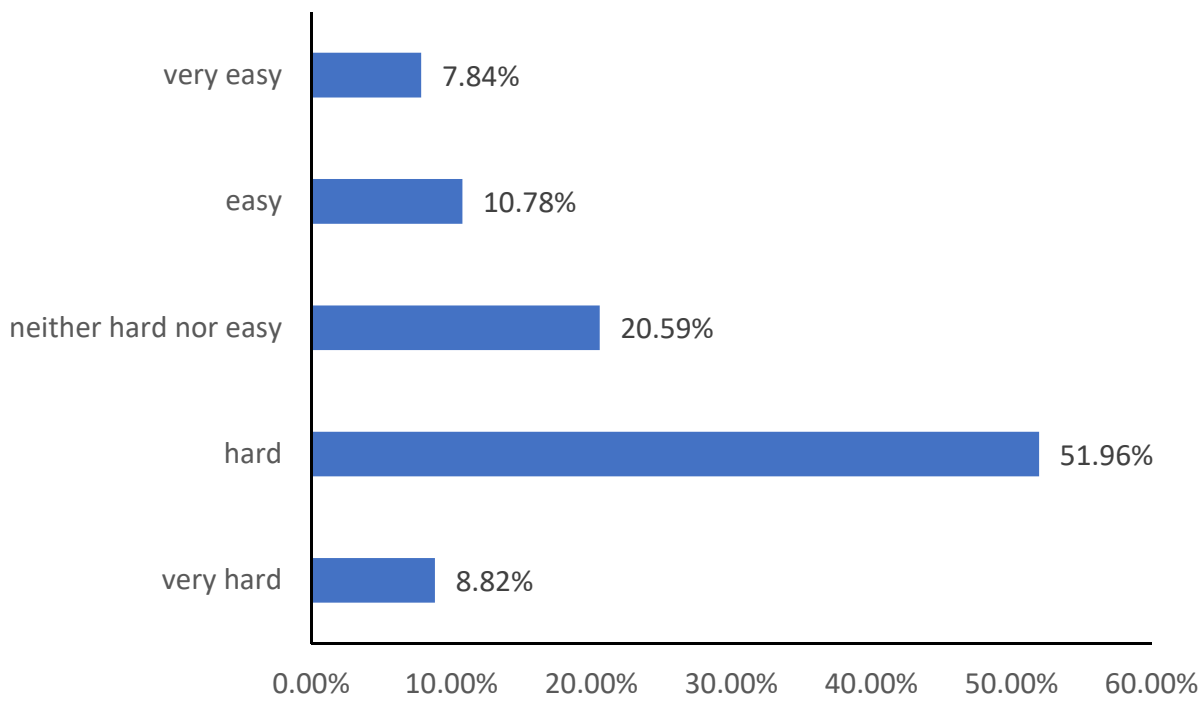

Figure 1. The way in which the transition from the standard to the remote form of work was carried out.

In the next step, the respondents were asked about the causes of problems related to the transition to the remote form of work (Figure 2). Most people, $87.75 \%$, stated that they were related to mutual communication. Considering the problem by gender, it was found that this view was expressed to a greater extent by women, $92.52 \%$, compared to $82.47 \%$ by men. In the analysis made depending on the age of the respondents, it was noticed that this problem became more significant with the age of the respondents: $91.55 \%$ of people over 41 years of age, $89.11 \% 25$ to 41 years of age. The lowest percentage of selections was obtained here in the group of people up to 25 years old, a total of $75 \%$. The second place in terms of the number of selections was the uncertainty of the future (both in terms of health and work) $-83.82 \%$. This position, as before, was marked more often by women: $89.72 \%$ compared to $77.32 \%$ men. As expected, this problem was indicated more often by older people: range, 3-91.55\%; second range, $86.14 \%$; first range (the youngest), $59.38 \%$. According to $69.12 \%$ of the respondents, home conditions were the basic problem. It should be assumed that this concerned the number of rooms, the workplace, and the sharing of equipment. This problem was indicated mainly by men, $74.23 \%$, compared to women, $64.49 \%$. As before, this problem was highlighted more often by the elderly. Problems related to the difficulties in adapting to the new working conditions (professional dimension) were declared by $64.71 \%$ of people. In this case, the majority of people pointing to the problem were women, $68.22 \%$, compared to men, $60.82 \%$. The problem was indicated more often by older people. Technical problems and access to the Internet and computer workstations were indicated by $47.55 \%$ of the respondents. The obtained distribution of answers depending on gender: $49.53 \%$ women, $45.36 \%$ men. Analyzing the problem depending on the age of the respondents, it was found that the largest share was taken by people aged 25 to 41 years, $54.46 \%$, compared to older people, $50.70 \%$, and people aged less than 25 years, $18.75 \%$. Meanwhile, $12.25 \%$ of people indicated no problems, and $11.27 \%$ indicated that it was difficult to say. 


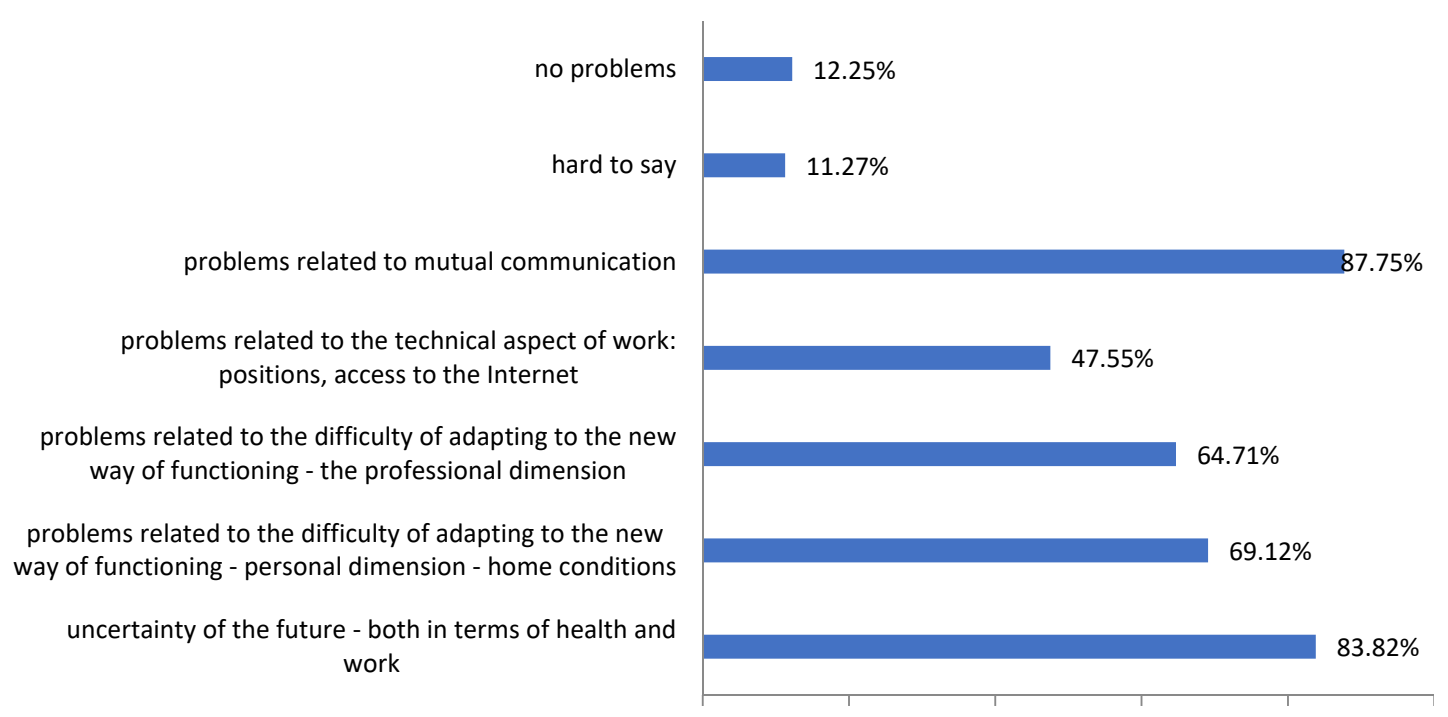

Figure 2. Problems related to the need to switch from the traditional to the remote form of work.

People are the most important element of the information system. Its effectiveness depends on them. Therefore, the respondents were asked about the impact of a sudden and forced transition to remote work on professional relationships in the enterprise (Figure 3).

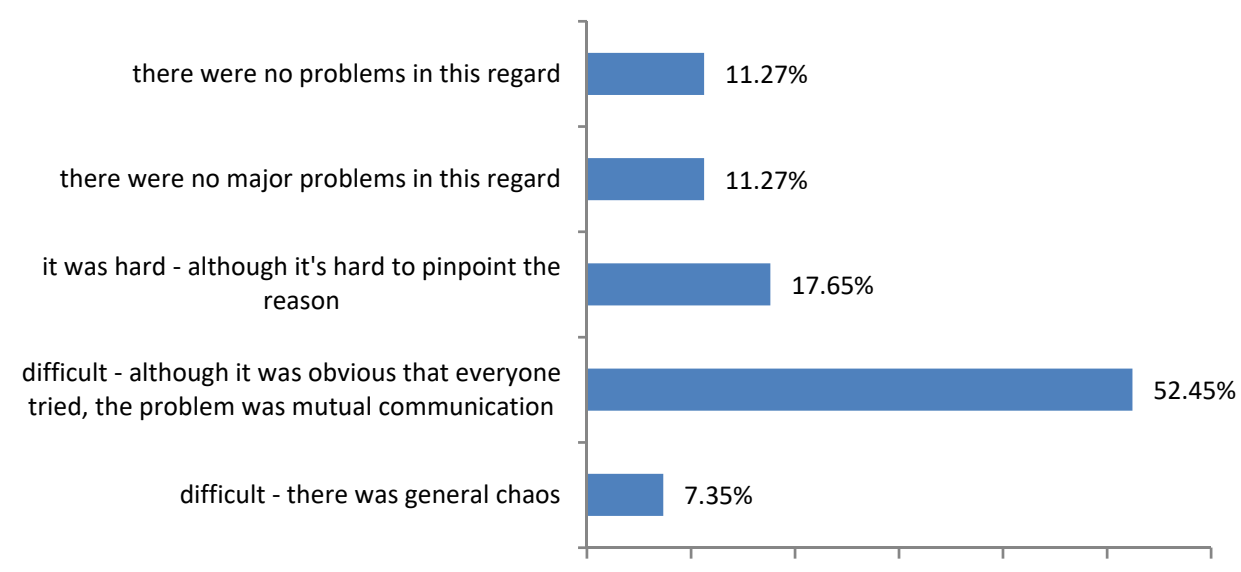

Figure 3. How respondents described the professional relationship in the initial period after switching to the remote mode.

As can be seen in Figure 3, 52.45\% of people stated that they had difficulties regarding relationships, and the reason for this state of affairs was communication between employees, as well as employees and management. Considering the problem depending on gender, it was found that this answer was indicated by $53.27 \%$ of women and $51.55 \%$ of men. The difficulties were reported mainly by people aged over $41,60.56 \%$, and those aged up to 25 years, $56.25 \%$. People aged 25 to 41 years of age jointly marked this position less frequently, $45.54 \%$. Meanwhile, $17.65 \%$ of the respondents said that relationships had deteriorated, but were unable to provide a reason. A similar trend was observed for this position, with the difference that there was a correlation: the percentage of responses increased with age. This item was more often marked by women, $19.63 \%$, than by men, $15.46 \%$. Feelings of general chaos were indicated by $7.35 \%$ of people as the cause of the deterioration of relations. This item was marked by more or less the same distribution of women and men: $7.48 \%$ women, $7.22 \%$ men. Additionally, here, an increase in the percentage of selections in the group of elderly people was observed. In turn, $11.27 \%$ of people declared that there were no major relationship problems. These positions were marked by a greater percentage by men. 
According to the results included in the previously quoted report "Voice of the European workforce", trust influences work, especially in crisis conditions. In a study by the authors of this publication, this influence was noted by $96.08 \%$ of respondents (Figure 4 ). At the same time, a majority of $73.04 \%$ of respondents indicated that the sudden and forced transition to remote work had an impact on trust in the company, but they were not able to indicate whether the impact was positive or negative. This difficulty could be related to the fact that relationship issues undoubtedly had a negative impact on trust. On the other hand, however, the necessity for the enterprise to function as a system could not be based on a lack of trust. Solving and overcoming problems in relationships had to be based on the mutual trust that had been established earlier in the course of work. A negative or very negative impact was marked by $13.72 \%$ of the respondents and, on the other hand, according to $13.23 \%$, it was marked as positive or very positive.

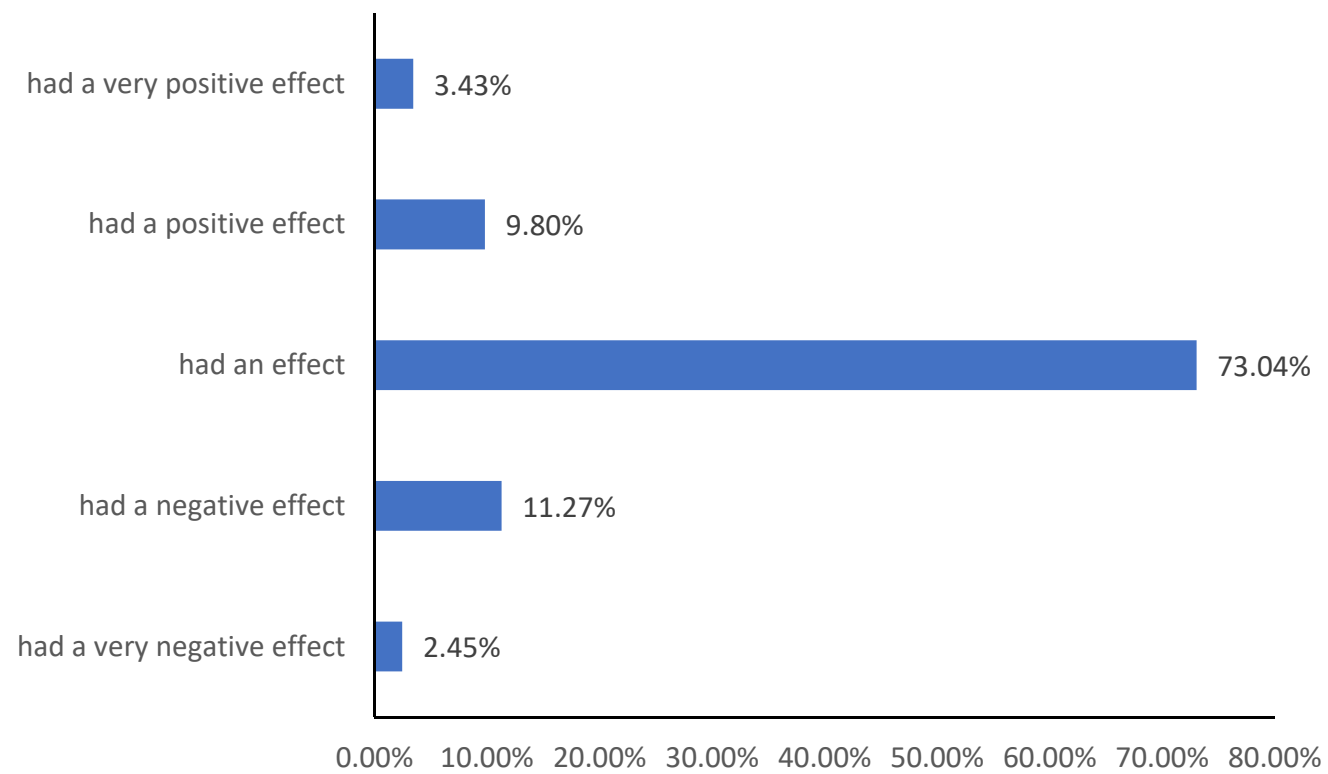

Figure 4. Did the necessity to switch to remote working mode in your opinion affect mutual trust at work?

The impact of trust on relationships in the context of the need to move to remote work is examined in the next question. According to $51.96 \%$ of people, trust influences relationships; $24.02 \%$ assessed it as high and $13.24 \%$ assessed it as decisive. Meanwhile, $3.43 \%$ of the respondents did not see the impact of trust on relationships, and $7.35 \%$ did not have an opinion in this respect. When analyzing the distribution of the obtained answers depending on the respondents' gender, it was found that women rated this influence more often than men as decisive or high, respectively: decisive, women $14.02 \%$, men $12.37 \%$; high: women $26.17 \%$, men $2165 \%$. On the other hand, men more often than women indicated that this influence is present or that it is not there, respectively: it is noticeable, men $53.61 \%$, women $50.47 \%$; none, men $4.12 \%$, women $2.80 \%$. The study also found that, with age, the belief in the impact of trust on relationships in the enterprise grows, including those in the situation of the need to suddenly switch to remote work: $81.26 \%$ of people aged up to $25,10 \%$ of people 25 to 41 years, and $91.55 \%$ of people over 41 years old. Younger people more often indicate that trust does not affect the relationships: $6.25 \%$ of people aged up to 25 years, $2.97 \%$, 25 to 41 years, and $2.82 \%$, over 41 years of age.

The issues of relations, communication, and finally trust in connection with the need to switch to remote work are undoubtedly related to the technical conditions of work. Therefore, the respondents were asked whether they had been provided with the necessary IT infrastructure in the company (Figure 5). Most people, $47.55 \%$, selected the answer no, $22.06 \%$ indicated that they had received the equipment immediately, $15.69 \%$ received the 
equipment within 2 months of the transition, and 14.71\% received the equipment more than 2 months after.

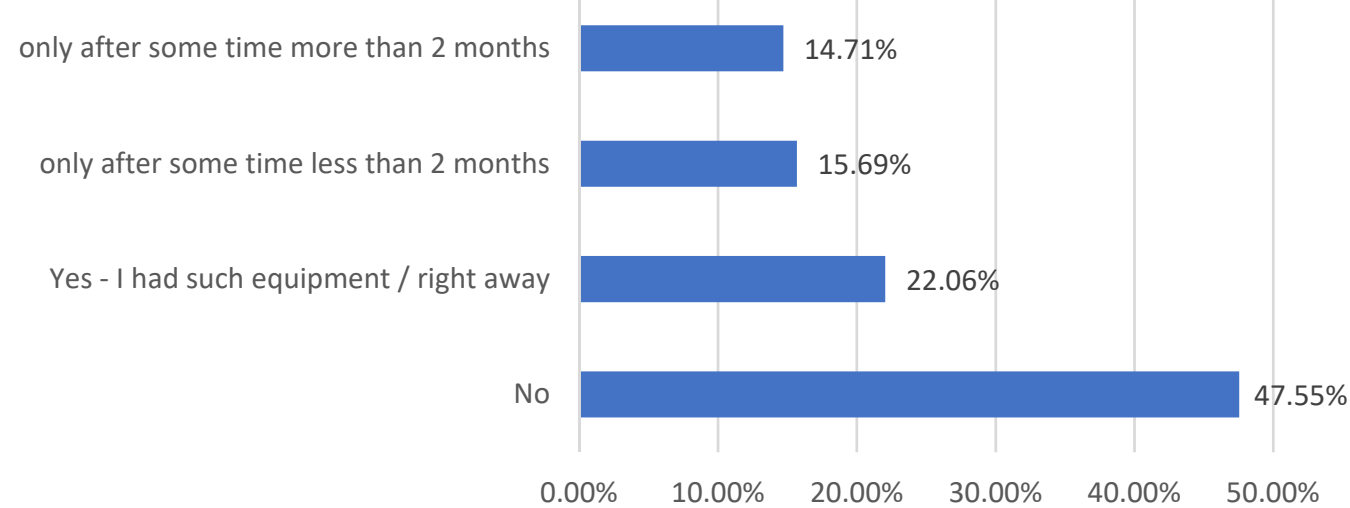

Figure 5. Due to the necessity to switch to remote work mode, have you been provided with business computer equipment?

The next problem taken up in the survey included the factors contributing to the positive effect of a sudden transition to a remote form of work. The respondents could select more than one answer here. The answer "type of conducted activity" was most appreciated-98.04\% of selections. This is due to the obvious dependence of the ability to work remotely on the company's business profile. In second place, in terms of the number of selections, was flexibility as a feature of the structure and functioning of the enterprise- $87.25 \%$. According to $82.84 \%$ of respondents, having experience in remote work counts in this respect. The distribution of answers to this question is presented in the Table 1.

Table 1. Main problems and development challenges of cities.

\begin{tabular}{ccc}
\hline & Number of People & Percentage \\
\hline experience in the remote work & 169 & $82.84 \%$ \\
\hline ensuring access to the necessary IT infrastructure & 65 & $31.86 \%$ \\
\hline $\begin{array}{c}\text { psychological factor - preparation for various situations } \\
\text { young age of employees-up to 40 years }\end{array}$ & 84 & $41.18 \%$ \\
\hline $\begin{array}{c}\text { flexibility as the feature of the enterprise-both in terms } \\
\text { of structure and work of employees }\end{array}$ & 178 & $15.20 \%$ \\
\hline $\begin{array}{c}\text { type of business } \\
\text { interpersonal relations }\end{array}$ & 200 & $87.25 \%$ \\
\hline $\begin{array}{c}\text { ensuring an efficient communication system in the } \\
\text { company (ensuring communication regardless of the } \\
\text { form of work) }\end{array}$ & 95 & $98.04 \%$ \\
\hline hard to say & 154 & $76.57 \%$ \\
\hline
\end{tabular}

Another problem raised was the increase in the individual costs of electricity consumption, which had to be borne by employees in connection with the need to perform their duties at their place of residence. According to $59.80 \%$ of respondents, individual costs of energy consumption increased. This fact was not noticed by $8.82 \%$ of the respondents, and $31.37 \%$ of them indicated the answer difficult to say. According to the authors of the publication, these costs have certainly increased. This is due to the fact that official duties while the employees were traditionally away from home had to be performed at home. There is also the use of energy in connection with the implementation of normal life activities: preparing meals, brewing coffee and/or tea, listening to the radio, or watching 
TV. This increase was proportional to the number of people in the family whose daily existence was limited to functioning in the place of residence. The increase in the cost of electricity consumption is also confirmed by the results of research carried out around the world, including Poland [44-46]. It should be noted that each of the reports indicates a decrease in consumption in the national dimension, with a simultaneous increase in consumption in the household dimension.

The last problem examined by the authors was the potential increase in the number of failures of devices related to the use of electricity, including those whose operation is based on data transmission. According to $85.78 \%$ of respondents, the necessity to switch to remote operation mode did not increase the number of failures. Only two people, representing $0.98 \%$ of the respondents, indicated that the number of failures increased. The position, is difficult to say, was marked by $13.24 \%$ of the respondents. This allows us to conclude that the necessity of a forced transition to remote work did not affect the number of home equipment failures.

\section{Discussion}

The sudden need to switch to remote work mode is a big challenge for companies. The problem, as indicated by the results of both the authors' and those cited in the content, is primarily a disturbance in the area of communication and mutual relations. These aspects of the company's operation are closely related to the functioning of the information system. This situation is a great threat to the company. Information, the flow of which is closely related to relations and communication, is the factor that powers economic activity.

This study confirmed the hypothesis according to which forced and sudden transition to remote work has a negative impact on the functioning of the company's information system. It was seen that $60.78 \%$ of the respondents stated that the transition was, for them, related to the occurrence of problems. The reasons for this negative impact include the aforementioned relationships and communication, psychological problems, and organizational factors. The mentioned organizational factors were related to professional work, but also to the home conditions in which the work took place. With sudden and unforeseen events with a large scale of impact, it is difficult to reconcile these two areas of human functioning and direct them to the achievement of private and professional goals without any problems. This issue is, in the authors' opinion, a research area that should be subjected to more detailed research. It should be assumed that this is one of the basic causes of disturbances in the area of communication and relationships.

Verification of another hypothesis, forced and sudden transition to remote work has a negative impact on trust in the enterprise, indicated that it was false. As the result of the research, it was found that, although the forced and sudden transition to remote work has an impact on trust, it cannot be indicated that this impact is clearly negative. At the same time, it turned out that remote work has a negative impact on relationships, which occurs especially in the initial period and is caused by communication problems, often caused by technical and organizational factors. Trust is the factor that allows companies to improve relationships over time. It should be assumed that this is related to trust that was developed at the stage of work in the traditional form. This, in turn, according to the authors, is another research area for the future. It concerns the time and the process of shaping trust in the enterprise and the impact of this trust as a factor on the ability and speed of adapting to sudden changes of great strength and scope.

Based on the conducted research, as well as on the results of the research to which the authors gained access, it can be concluded that the need to switch to remote work had an impact on the increase in the costs of individual employees resulting from electricity consumption. At the same time, as indicated in the reports, the national levels of electricity consumption have decreased. Increasing the level of energy consumption as well as the overall lifetime of electricity and data transmission devices did not increase the number of failures in households. 
An important conclusion from the conducted research is the identification of factors that may allow one, in the future, to avoid or reduce the impact of problems related to the occurrence of negative events of a wide and even global scope. As the respondents indicated, these include: flexibility (structure, work), experience in remote working, organization of the communication system, effective on various levels, and shaping the appropriate organizational culture based on trust and close relationships. It is also important to conduct psychological activities with employees, which will allow one to relieve stress and prepare for functioning in an unstable reality. According to the authors, it is also important to constantly control the resources at hand and organize the necessary technical infrastructure related to the remote mode of operation. The significance of the presented factors can be described as follows:

- Type of business - one of the most important factors influencing the ability and effectiveness of the sudden transition to remote work. The situation is completely different in the case of companies with a production profile that uses specialized equipment, and different again in the case of small-scale production, for which simple and accessible technical infrastructure is required. Another situation concerns organizations dealing with intellectual work, in which computers and software are the basic working tools. Good examples of differences in capacity are establishments that provide stationary room rentals - hotels—and organizations that rent apartments in different parts of the city;

- An appropriately shaped form of organizational culture-this is the most general factor that has an impact on all relations and relationships at work. It also has a large impact on the employees' approach to work, which is especially important in crisis situations. It is also important that an appropriate organizational culture in the workplace has a positive impact on solving personal problems. This aspect plays an important role precisely in crisis situations with a wide range of impacts. COVID-19 has disrupted both work and private life. The effects of appropriate organizational cultures, including through the calmness of the form and the course of work, as well as the support of other employees, have a positive impact on the private life of employees. Thus, on the basis of feedback, they positively affect work efficiency and maintain organizational culture;

- Flexibility in the structure and form of work-the abolition of rigid structures as well as relationships and rules of work (in enterprises where such a possibility is available) by its nature ensures the possibility of better adaptation to crisis situations/disruptions caused by various events, including those of an epidemiological nature. The organization is an entity that is able to adapt to market requirements in the dynamic and global reality. Given the speed and extent of market changes prior to the pandemic, it is better able to cope with pandemic situations. This applies to both the technical and the interpersonal aspects. At the same time, it should be emphasized that flexibility requires an appropriately shaped and oriented form of organizational culture;

- Experience in performing professional duties remotely - the factor that, by nature, allows for the reduction of the negative effects of the pandemic. Employees and entire companies with only limited experience in this regard need to adapt to the new situation. Experience also allows one to carry out this process more efficiently and faster;

- Organization of an effective communication system - communication is the basis for the effectiveness of human functioning, including at the professional level. Providing an appropriate communication system that allows for free communication, both in real and remote dimensions, if necessary, and group communication, e.g., brainstorming, exchange of experiences, and help, allows one to maintain work efficiency in various situations. This is especially important in the conditions of epidemiological threats, as the result of which work must be carried out remotely; 
- Organization of the possessed/at disposal IT facilities (computer stations with the necessary software made available to employees) - this is an important technical factor of the ability to suddenly switch to the remote form of work. Employees who do not have official equipment provided have to organize it on their own, which, in the conditions of a widespread health risk, especially in relation to children and parents, was not easy. An even more significant problem is the provision of the software necessary for remote work;

- Acceptance-this is the psychological factor related to accepting problems and realizing the need to function in a new reality. This factor is influenced by the appropriate organizational culture, interpersonal relations, and psychophysical abilities.

The management should monitor the employees' ability to smoothly switch to remote work, and on this basis plan their own actions in various situations.

Based on the research, it was also found that the transition to forced remote work is a more significant problem for women. At the same time, women are more aware than men of the influence of trust on relationships. For men, one of the most important problems was adjusting the performance of work tasks to home requirements-remote work at home. For women, the problem was uncertainty of the future, communication, and adjusting to new working conditions. It was also found that, in crisis situations, related to, e.g., the necessity to switch to a forced, remote form of work, experience in conditions resulting from the new situation is more important than experience of years of work. With increased age, adjusting to a new reality becomes more difficult. Undoubtedly, this was also influenced by health risks, which become an increasingly important factor in life with the passage of time.

\section{Conclusions}

In this work, the results of qualitative and quantitative research conducted by the authors were used. The use of the chosen methodologies was related to the fact that quantitative research allows one to obtain a generalized picture of the subject of the research. On the other hand, qualitative research allows one to gain more knowledge related to the identification of factors related to the studied area and the relationships between them. The preparation of the questionnaire required the acquisition of specific knowledge, as well as the identification and understanding of specific factors and the relationships between them. This required the use of qualitative research methodology. Qualitative research based on the idea of ethnographic research allows one to better understand the details of the phenomenon, while quantitative research allows for generalizations.

The implementation of research is always associated with the occurrence of specific problems and limitations. In the case of the research conducted for the purposes of this publication, the general problem was access to respondents-quantitative research and people interested in conducting interviews and participating in discussions. The problem was not with the observation. It should be noted that this was related to the time of the research being during the period of the COVID-19 pandemic. This time was, moreover, the basic factor contributing to the problems that are the subject of this publication. Therefore, an observation was facilitated, which resulted directly from the prevalence of the phenomenon of switching to a remote form of work and the emergence of related disruptions in the functioning of the individual and enterprises.

After completing the research procedure, the authors found certain limitations and drawbacks. Their identification will allow for the continuation of research in the future. Importantly, researchers will be able to avoid the identified drawbacks and limitations. Among them, the following should be indicated:

- Increasing the number of respondents. Here, attention should be paid to the diversity of the respondents in terms of the size of the enterprise, its market experience, its industry, and the form of the organizational structure, etc.

- In research, attention should be paid to the reference to factors of a motivational/control nature. Including the issue of KPIs or other control tools (motivating) in the research will undoubtedly increase the value of the analysis and conclusions. The importance 
of motivating tools as elements of counteracting the mental problems of employees that occur in connection with unpredictable events of a scale comparable to COVID-19 should be emphasized. Employees without these tools may have problems with the normal performance of previous tasks,

- Qualitative research plays an important role in this type of research. It is important due to, inter alia, its social nature. As in the case of quantitative research, it is suggested that it is performed with a larger number of different entities. This, in turn, requires involving more researchers. The authors believe that cooperation is a very important issue in the research included in this work. It enables better understanding and analysis of the problem.

Author Contributions: Conceptualization, T.L., A.P. and M.L.; methodology, T.L., A.P. and M.L.; formal analysis, T.L., A.P. and M.L.; resources, T.L., A.P. and M.L.; data curation, T.L., A.P. and M.L.; writing—original draft preparation, T.L.; writing—review and editing, T.L., A.P. and M.L.; supervision, T.L., A.P. and M.L. All authors have read and agreed to the published version of the manuscript.

Funding: The APC was funded by Czestochowa University of Technology.

Institutional Review Board Statement: Not applicable.

Informed Consent Statement: Not applicable.

Data Availability Statement: Not applicable.

Conflicts of Interest: The authors declare no conflict of interest.

\section{References}

1. Singh, K.; Kaur, B. Role of Management Information System in Business: Opportunities and Challenges. Gian Jyoti 2012, 1, 1-10.

2. Girard, J.P.; Girard, J. Defining knowledge management: Toward an applied compendium. J. Appl. Knowl. Manag. 2015, 3, 1-20.

3. Mithas, S.; Ramasubbu, N.; Sambamurthy, V. How Information Management Capability Influences Firm Performance. MIS Q. 2011, 35, 237-256. [CrossRef]

4. Choo, C.W. Information culture and organizational effectiveness. Int. J. Inf. Manag. 2013, 33, 775-779. [CrossRef]

5. Holland, P.; Cooper, B.K.; Pyman, A.; Teicher, J. Trust in management: The role of employee voicearrangements and perceived managerial oppositionto unions. Hum. Resour. Manag. J. 2012, 22, 377-391. [CrossRef]

6. Blake, I.; Learmonth, G.P. The information system as a competitive weapon. Commun. ACM 1984, $27,1193-1201$.

7. Kisielnicki, J. Management Information Systems; Placet: Warszawa, Poland, 2013; pp. 55-89.

8. Imache, R.; Izza, S.; Ahmed-Nacer, M. An enterprise information system agility assessment model. Comput. Sci. Inf. Syst. 2012, 9, 107-133. [CrossRef]

9. Larsen, T.J.; Sorebo, A.M.; Sorebo, O. The role of task-technology fit as users' motivation to continue information system use. Comput. Hum. Behav. 2009, 25, 778-784. [CrossRef]

10. Dziekański, P. Information as an economic good which is a source of competitive advantage. Soc. Inequalities Econ. Growth 2012, 24, 387-403.

11. Davidavičien, V. Change Management Decisions in the Information Age. J. Bus. Econ. Manag. 2008, 9, 299-307. [CrossRef]

12. Citroen, C.L. The role of information in strategic decision-making. Int. J. Inf. Manag. 2011, 31, 493-501. [CrossRef]

13. Parast, M.M.; Sabahi, S.; Kamalahmadi, M. The Relationship Between Firm Resilience to Supply Chain Disruptions and Firm Innovation. In Revisiting Supply Chain Risk; Springer Series in Supply Chain Management; Zsidisin, G., Henke, M., Eds.; Springer: Cham, Switzerland, 2019; Volume 7, pp. 279-298.

14. Kisielnicki, J.; Sroka, H. Business Information Systems; Placet: Warszawa, Poland, 2011; p. 9.

15. Szaniawska, A.; Grochowska, A. Information System in Managing a Contemporary Organization; Scientific Journals of the University of Natural Sciences and Humanities in Siedlce, Nr 103; University of Natural Sciences and Humanities: Siedlce, Poland, 2014; p. 300.

16. Hartwick, J.; Barki, H. Explaining the Role of User Participation in Information System Use. Manag. Sci. 1994, 40, 429-548. [CrossRef]

17. Melchor, M.Q.; Julián, C.P. The Impact of the Human Element in the Information Systems Quality for Decision Making and User Satisfaction. J. Comput. Inf. Syst. 2008, 48, 44-52.

18. Belzunegui-Eraso, A.; Erro-Garcés, A. Teleworking in the Context of the COVID-19 Crisis. Sustainability 2020, 12, 3662. [CrossRef]

19. De Vries, H.; Tummers, L.; Bekkers, V. The Benefits of Teleworking in the Public Sector: Reality or Rhetoric? Rev. Public Pers. Adm. 2019, 39, 571-573. [CrossRef] 
20. Organization of Remote Work Step by Step. Available online: https://blog.assecobs.pl/organizacja-pracy-zdalnej-krok-pokroku/ (accessed on 10 March 2021).

21. Messenger, J.C.; Gschwind, L. Three generations of Telework: New ICTs and the Revolution from Home Office to Virtual Office. New Technol. Work Employ. 2016, 31, 195-208. [CrossRef]

22. Bélanger, F.; Allport, C.D. Collaborative technologies in knowledge telework: An exploratory study. Inf. Syst. J. 2008, 18, 101-121. [CrossRef]

23. Remote Work in the Times of Coronavirus. Available online: https://www.rp.pl/Kadry/310149957-Praca-zdalna-w-czasachkoronawirusa-80-proc-pracownikow-musi-byc-obecnych-w-firmach.html (accessed on 10 March 2021).

24. Possibilities of Using Remote Work in Enterprises and Public Institutions. pp. 59-60. Available online: http:/ / www.dwup.pl/ asset/images / files/Raport_20201016.pdf (accessed on 26 October 2021).

25. Hristov, I.; Chirico, A. The Role of Sustainability Key Performance Indicators (KPIs) in Implementing Sustainable Strategies. Sustainability 2019, 11, 5742. [CrossRef]

26. Almost $60 \%$ of Employees Want Remote Work to Stay. Available online: https://mojafirma.infor.pl/biznes/zarzadzanie/519233 1,Prawie-60-pracownikow-chce-aby-praca-zdalna-zostala-BADANIE.html (accessed on 10 March 2021).

27. Benkerrou, H.; Heddad, S.; Omar, M. Credit and Honesty-Based Trust Assessment for Hierarchical Collaborative IoT Systems. In Proceedings of the 2016 7th International Conference on Sciences of Electronics, Technologies of Information and Telecommunications (SETIT), Hammamet, Tunisia, 28-20 December 2016; Institute of Electrical and Electronics Engineers: Piscataway, NJ, USA, 2016; pp. 295-299.

28. Rudzewicz, A. Trust in the enterprise-Meaning and measurement. J. Manag. Financ. 2017, 15, 291.

29. Shepherd, N.G.; Mooi, E.A.; Elbanna, S.; Rudd, J.M. Deciding Fast: Examining the Relationship between Strategic Decision Speed and Decision Quality across Multiple Environmental Contexts. Eur. Manag. Rev. 2021, 18, 119-140. [CrossRef]

30. Dowell, D.; Morrison, M.; Heffernan, T. The changing importance of affective trust and cognitive trust across the relationship lifecycle: A study of business-to-business relationships. Ind. Mark. Manag. 2015, 44, 119-130. [CrossRef]

31. Bouma, J.; Bulte, E.; van Soest, D. Trust and cooperation: Social capital and community resource management. J. Environ. Econ. Manag. 2008, 56, 155-166. [CrossRef]

32. Yeon, J.; Park, I.; Lee, D. What creates trust and who gets loyalty in social commerce? J. Retail. Consum. Serv. 2019, 50, 138-144. [CrossRef]

33. Perry, S.J.; Rubino, C.; Hunter, E.M. Stress in remote work: Two studies testing the Demand-Control-Person model. Eur. J. Work Organ. Psychol. 2018, 27, 577-593. [CrossRef]

34. Ok-Kyu, C.; Erin, C. The mechanism of trust affecting collaboration in virtual teams and the moderating roles of the culture of autonomy and task complexity. Comput. Hum. Behav. 2019, 91, 305-315.

35. Chmielewska-Muciek, D. Managers' perception of organisational culture. Mark. Soc. Cult. 2017, 2, $104-108$.

36. Ribiere, V.M. Building a Knowledge-Centered Culture: A Master of Trust. In Creating the Discipline of Knowledge Management. The Latest in University Research; Stankosky, M., Ed.; Butter-Heinemann Elsvier Ltd.: Oxford, UK, 2005; pp. 1-7.

37. Kuo, T.H. How expected benefit and trust influence knowledge sharing. Ind. Manag. Data Syst. 2013, 113, 506-522. [CrossRef]

38. Józefowicz, B. Building Organizational Trust in an Enterprise; Scientific Journals of the University of Szczecin, Studies and Works of the Faculty of Economics and Management. Nr 39 T.2; University of Szczecin: Szczecin, Poland, 2015; pp. 195-206.

39. Gerlach, J.; Gil, M. Enterprise efficiency in the theory of economics—Which by definition best describes the essence of the issue? Contemp. Econ. Probl. 2018, 2, 14.

40. Mazurek-Łopacińska, K.; Sobocińska, M. Triangulation in Qualitative Research; Scientific Papers of the University of Economics in Wrocław, Nr 525; University of Economics in Wrocław: Wroclaw, Poland, 2018; p. 13.

41. Silverman, D. Conducting Qualitative Research; Polish Scientific Publishers PWN: Warszawa, Poland, $2010 ;$ pp. $161-162$.

42. Konecki, K.T.; Chomczyński, P. (Eds.) Dictionary of Qualitative Sociology; Difin: Warszawa, Poland, 2012; pp. $185-189$.

43. Worek, B.; Perek-Białas, J. Creation of Concept Maps. A Qualitative Technique for the Reconstruction of Cognitive Processes. In Quantitative and Qualitative Methods of Market Research. Measurement and Its Effectiveness; Garczarczyk, J., Ed.; Poznań University of Economics and Business Press: Poznań, Poland, 2006; pp. 165-178.

44. Coronavirus. In Spain, They Want to Lower Electricity Prices. Available online: https://www.money.pl/gospodarka/ koronawirus-w-hiszpanii-chca-obnizyc-ceny-za-prad-6616363034102336a.html (accessed on 10 September 2021).

45. During the Pandemic, Energy Demand in Industry Decreases, but Consumption by Households Increases. Available online: https:/ / www.cire.pl/artykuly/serwis-informacyjny-cire-24/156921-w-czasie-pandemii-spada-popyt-na-energie-wprzemysle,-ale-wzrasta-zuzycie-przez-gospodarstwa-domowe (accessed on 10 September 2021).

46. Soava, G.; Mehedintu, A.; Sterpu, M.; Grecu, E. The Impact of the COVID-19 Pandemic on Electricity Consumption and Economic Growth in Romania. Energies 2021, 14, 2394. [CrossRef] 